Open Access

\title{
Reconstructing "nation" (minzu) discourses in China
}

Rong Ma

Correspondence:

marong@pku.edu.cn

Department of Sociology, Institute

of Sociology and Anthropology,

Peking University, Beijing 100871,

China

\begin{abstract}
Due to the great gap between the official "nation" (minzu 民族) discourse-policy goals of the Chinese government and the social realities of ethnic relations in China, it is necessary for the leadership, academics, and the public in China to review the historical process involved in creating the "nationality" discourse dynamics of the past century. Chinese need to understand the nature of "nation" as it appears in international discourse, while still retaining a connection to the inherited Chinese cultural traditions which have assisted in managing group relations for thousand years. Based on international experience and historical lessons, China should eventually reconstruct its own "nation" (minzu) discourse system, thereby developing a new system and policies to manage ethnic relations based on a new theoretical framework. One emphasis in this transition should be citizenship with equal rights for every citizen regardless ethnic background. Another emphasis should be the rule of the law in dealing with the "nation/ethnicity" issues in China. In order to transfer to a civic society, the "political colors" that favor 'nation' (minzu) in relation to status, prestige, advantages in the judiciary system or distribution of welfare benefits should be weakened. Based on the suggested "de-politicization" of the 56 "nationalities" (minzu) of China, the author suggests the employment of national laws to deal equitably with the events and differences between the various "nationality" (minzu) groups instead of the preferential policies currently employed in favor of certain minority groups.
\end{abstract}

Keywords: Issues of "nation"(minzu), "De-politicization of ethnicity", Ethnic policy; discourse system

\section{Background}

"Nation," "nation-state" and "nationalism" are western concepts that emerged in Europe around the 16-17th centuries (Kedourie, 1960; Gellner, 1983; Hobsbawm, 1990) and were introduced into China in late nineteenth century after the Opium War. After the October Revolution, Stalin's "nation/nationality" theory and practice of the USSR were also introduced into China and have strongly influenced the People's Republic of China since 1949. In today's China, the Chinese nation is called "zhonghua minzu" (Chinese nation 中华民族), the 56 ethnic groups (Han, Tibetans, Mongols, Manchu, etc.) within China are called 56 "minzu 民族” (the official English translation is 56 "nationalities"). Because the same Chinese term "minzu (民族)" is used at two different levels, this usage has caused much confusion among both Chinese people and foreigners. Since these concepts are subject to different interpretations and many misunderstandings in modern Chinese society and have led to serious debates regarding these concepts and

(c) The Author(s). 2017 Open Access This article is distributed under the terms of the Creative Commons Attribution 4.0 International License (http://creativecommons.org/licenses/by/4.0/), which permits unrestricted use, distribution, and reproduction in any medium, provided you give appropriate credit to the original author(s) and the source, provide a link to the Creative Commons license, and indicate if changes were made. 
their practice among the scholars and government officers in China, reconstructing a new "nation/nationality" (minzu) discourse becomes urgent.

The transformation of the relations among "nationalities" (minzu) in China

My understanding of "nation/nationality/minzu" issues in China is mainly based on my personal experiences and fieldwork over several decades. During the early period of Cultural Revolution in the mid-1960s, I travelled over half of China by train and on foot as a Red Guard. Evident at the gathering parties, everywhere, there were joyful revolutionary emotions that radiated from the youthful Red Guards from different groups. There was only "class identity" or "revolutionary comradeship" among us while "nationality (minzu) identity" was ignored. During 1968-1973, I lived in a nomadic community in Inner Mongolia as a herdsman. Through daily contact with Mongol nomads, I was strongly impressed by their kindness and honesty. My friendship with local Mongol herdsmen has lasted until today. Until the middle of the 1980s, for me and for others I was in contact with who had different ethnic backgrounds, the identity and differentiation of "nationality" (minzu) seemed unimportant; the term reflected only differences in languages and customs. Indeed, in daily communications, people paid much more attention to other's personalities rather than their "nationality" (minzu) status.

During 1982-1987, I studied sociology at Brown University in the US, where ethnicity was one of the major issues discussed in the classroom. I feel that the term "ethnic groups" as used in the US is a better term to call Mongols, Tibetans, Manchu and other minority groups in China. The English term "ethnic group" was translated into the Chinese term “zuqun 族群” by Taiwan/Hong Kong scholars in the 1960s. The comparison of these two terms in Chinese (minzu 民族 vs. zuqun 族群) indicates two models of interpretation of ethnic minorities in a multi-ethnic country.

In 1987, I joined the faculty at Peking University after graduation. I went to Lhasa to conduct a questionnaire survey and carry out household interviews in the next year (Ma Rong, 2011a). From that time onward, the issues of "minzu/ethnic relations" captured my attention in my following field-work in Tibet, Inner Mongolia, Xinjiang, Qinghai, Gansu and other minority regions. In interviews of local officials, scholars and residents, I observed the identity barriers between Han and Tibetans after the street violence in Lhasa and I was also strongly impressed by ethnic tensions during my interviews in Kashgar, Xinjiang, in 1997.

The main issues I have studied in the west regions of China in the past 30 years include: residential and intermarriage patterns between ethnic groups (Ma Rong and Pan Naigu, 1988; Ma Rong, 1991), rural-urban migration and cross-provincial labor migration of minorities, the job competition and unemployment of minorities (Ma Rong, 2003), the social reaction of preferential policies toward ethnic minorities, the parallel school systems and the bilingual education for minority students (Ma Rong, 2007, 2009), poverty alleviation in rural and urban areas and the results of government poverty-relief projects (Ma Rong, 2011b), changes in occupational and industrial structures of minority laborers, the reconstruction of old urban districts in minority areas (Ma Rong, 2011c, 2013a), the results of official "pairing-assistance" projects between eastern provinces and Xinjiang/Tibet Autonomous Region (Ma Rong, 2011d), social mobility and policies towards minority government employees, and the national projects of schooling for Tibetan and Uyghur students in eastern China (Ma Rong, 2016). 
From my field studies and interviews, I came to realize that the consciousness of "minzu identity" among some minority officials and intellectuals was much stronger than their identity toward the PRC state [国家] and they came to consider and interpret almost all social issues related to ethnic interactions (such as job competition in the labor market, benefit distribution of resource development projects, language study in schools, inter-regional income gaps, etc.) with the perspective of "nationality/minzu relations". Many social contradictions that could also occur in eastern China where the Han majority reside are promoted to "political conflicts" affecting the "rights and interests of minority nationalities/minzu". In all these treatments of social issues and problems, the discourses they employed were from the orthodox Marxist "nation (minzu) theories" they learned from school. Such an impression is in sharp contrast with my experience in the pre-1980s. Compared to the minority officers and intellectuals, the ordinary minority nomads and peasants who were not educated in "nation (minzu) theories" communicated in an open and forth right way with with members of other groups. The comparison of minority officers/intellectuals from different historical periods (the 1950s-1980s vs. post-1980s) and the comparison of the "nation (minzu) consciousness" of minority elites with ordinary members of ethnic minorities, are in great contrast to the "nation (minzu) theories" I learned in the past.

\section{The gap between present nationality/minzu theories - policies and social realities}

In the course of my field studies, I have found that text books on "nation (minzu) theories" compiled by the government cannot guide us to understand new contradictions between groups and cannot provide a solution to deal with them. There is an obvious gap between existing "nation (minzu) theories" and the social realities. Thus, it is necessary to reconstruct a new "nation (minzu)" discourse based on social realities according to the spirit of "seeking truth from facts" and to ponder whether it's necessary to adjust current institutions and policies.

In my paper entitled "Several issues in nation (minzu) studies" published in 2000, I pointed out that the tie between a minority group and a region should be gradually weakened. The roles played by institutions to guarantee all citizens' rights (including minority group members) should be gradually transferred from local executive structures to the operations of the national legal system. I suggested to de-politicize "nationality/ minzu" issues in China and to treat minority groups rather in the cultural perspectives. In adjusting the relative terms, I prefer to keep the term “Zhonghua minzu” (中华民族) unchanged as a counterpart of the English term "Chinese nation," while change the term of “56 minzu (民族)” to be “56 zuqun (族群)” corresponding to the English term "ethnic groups (Ma Rong, 2000)." After this thesis, from perspectives and positions people employed to see things around them, I began to study issues of ethnic/minzu relations in China for the purpose of constructing the consciousness of a common basic identity among ethnic minorities in China. Thus in 2004, I explicitly called for the "de-politicization" of the "nation/minzu" issues in China (Ma Rong, 2004). In 2010, I systematically discussed a dual structure of "Han vs. minorities" in Chinese society and its advantages and disadvantages in the nation-building process (Ma Rong, 2010a; Ma Rong, 2013b).

My personal experience in past studies of the grass-root society motivated me to see China's ethnic relations in terms of classic theories and to reflect and theorize their 
frameworks and operating mechanisms. I tried to figure out how Marxism classicists such as Karl Marx, Friedrich Engels, Vladimir Lenin, and Joseph Stalin addressed national issues as well as the documents ofthe Chinese Communist Party and the Chinese government. My impression is that quotations and citations of Marxist works in present Chinese textbooks didn't provide a systematic theoretic tool for solving today's "nation/ minzu" issues; and that we need an in-depth interpretation of those classics under the historical background when these classics were written. In 2012, in a paper entitled "How to understand 'minzu'(nation) and 'minzu zhuyi'(nationalism) in Marx and Engels' works, "I pointed out that Marx and Engels did not provide a systematic "theory of nation;" they didn't even define the core concept of "nation." For them, "nation" and "nationalism" are ideological weapons employed by capitalists of all countries to divide and disintegrate international workers' movements (Ma Rong, 2012). The "Marxism-Leninism theory of nation" publicized after the founding of new China was in fact from Stalin, whose major work on this issue was "Marxism and national issues" published in 1913, in which he raised the definition of "nation" (territory, language, economy and cultural identity) (Stalin, 1942). According to Stalin, minorities in Russia such as Ukrainians, Kazakhs, and Georgians are all "nationalities," and all have the right of self-determination, that is, the right to build their own independent states. Through analyses of different social classes and political struggles of the Russian society at that time, I found that essentially Stalin's "nation/nationality" theory was a strategy of a weak working class and its leading party (Bolshevik) to seize power under the specific historical social conditions in Russia in the early twentieth century. The theory itself, the "nationality recognition" campaign undertaken after the October Revolution, and the confederate system based upon the union of different "nationalities" in the Soviet Union, actually contributed to its disintegration in 1991 (Ma Rong, 2010b).

To these of my opinions, many Chinese scholars added their points of views from different positions (Leibold, 2013, Ma Rong, 2014). Along the traditional theoretic line of "nationality/minzu," the first group of scholars supports the classic Stalin theory. One of them said openly that there is no "Zhonghua Minzu"(Chinese nation) existing in China, except “56minzus (nationalities)"(Du Yonghao, 2010). Some scholars believed that the biggest problem at present is that the practice and realization of the Autonomy Law for Minzu (ethnic minority) Regions are insufficient; of all 155 autonomous units in China, there were still 15 that did not issue autonomous regulations according to the Autonomy Law; autonomy is possible only with autonomous regulations in practice (Hao shiyuan, 2013:81). So for them, the biggest task to undertake at the moment for the adherence and improvement of minority autonomous rights is to legislate detailed autonomous regulations for autonomous regions at all levels. The scholars criticized the commission system for minority affairs across the country, suggesting it should become a much more powerful division of the government to implement official policies for minorities. They believed that to strengthen the position and power of the commission system for minority affairs would benefit the practice of the CCP's policies for minorities (Hao Shiyuan, 2013).

The second group of scholars, on the contrary, in one way or another supports me to varying degrees. One published a paper in Xuexi Shibao [Study Times] edited by the Central School of CCP, in which it was explicitly stated that we should "enhance members of all groups to identify themselves with the motherland, the Zhonghua Minzu (Chinese nation), Chinese Culture, and with the Chinese characterized socialist path. Now, some of 
our educational and administrative measures consciously or unconsciously weakened people's identification with the state and their identification with the Chinese nation....The basic orientation of the work for minorities should respect ethnic differences, subsuming diversities and enhancing ethnic communications and integration. Personally, I incline to the policy to abolish the 'nationality/minzu' identity on the ID card of citizens, to stop setting up new autonomous areas for minorities, and to let students of different groups intermingle and study together in schools"(Zhu Weiqun, 2012). Some scholars even raised a proposal to change the policy towards minorities with a goal of "the transformation of the first generation of the policy which focuses on the recognition of 56 'nationality/minzus' and on keeping the national unity while developing all groups," leading to "the second generation policy, which is to promote the intermingling of all groups as a single body to advance the prosperity and to develop a great rejuvenation of the single unity of the Chinese nation"(Hu Angang and Hu Lianhe, 2011).

Each of these points of view is stated with clear positions, waging debates with each other in a tit-for-tat manner, breaking the dull and inactive situation of many years in the academic field of "nation studies" (Ma Rong, 2015). After the terrorist events that took place in some parts of China and the resulting academic discussions in the field of the "nation/minzu" theoretic policy, the public in China has begun to pay attention to "minzu" (nation/ethnicity) issues.

\section{Transformation of the ideological system of "nation (minzu)" discourse}

The present situation of ethnic relations in China is quite different from that in the 1950s, 1960s and even the 1970s. At the beginning of the 1950s, the PLA quickly liberated western areas inhabited by minorities in Tibet, Qinghai, and Xinjiang followed by the "land reform" movements. In "land reform," the working teams of PLA motivated poor people of local ethnic groups to overthrow traditional local authorities, religious or secular. For example, the PLA encouraged Tibetan serfs to oppose serf-owners in Tibet, and encouraged poor Uyghur farmers to oppose landlords in Xinjiang. The lands, live stock, housing and other goods of serf-owners and landlords were confiscated and redistributed among local poor people, equally and for free. These actions liberated poor people in terms of personal freedom and economic survival, and they whole-heartedly embraced the CCP and the new government. From that time until the end of the Cultural Revolution, the grouping of people in Chinese society, including frontier areas, was done according to their identities of "social class;" the social movement and personal relations were guided by the "class struggle" orientation; and the members of different ethnic groups were all "class brothers/ sisters" and "revolutionary comrades". All people loved Chairman Mao and embraced the Communist Party. The above conclusion is based on my personal communication during the Cultural Revolution and my life experience in a nomadic community in Inner Mongolia.

The "class struggle" ideology was criticized after the death of Mao Zedong, thus ending the Cultural Revolution in 1976, resulting in the weakening of the related "class identity" orientation. In the following campaign of "bringing things out of chaos and going back to the right track," the goal emphasized the implementation of policies focusing on ethnic minorities and religious activities instead of "class struggle" in minority areas. At that point, some people began to interpret the Cultural Revolution from the perspective of 
"ethnic/minzu interactions." The Cultural Revolution was described, from this standpoint, as a political movement in which the Han majority oppressed minorities. The turning point was marked by some leaders' speeches and the policies formulated after that. From that time onward, a strong political atmosphere of the "ethnic/minzu identity" among people and a strong political atmosphere in ethnic relations began to appear. Such a political interpretation of "nationality/minzu" for ethnic minorities was maintained and promoted ethnic nationalism. In the subsequent process of system reform and development of market economy, the people in minority areas began to interpret all kinds of social problems, economic competitions and cultural conflicts from the perspective of "the conflicts of nationality/minzu interest." This fundamental transformation of the basic system of the identity ideology in China changed the political tone and the emotional aspect of the daily contacts and communications between members of different ethnic/minzu groups.

From my point of view, it is not proper to call the 56 groups in China "nationalities" since they together compose the Chinese nation. These groups share many characteristics in common as a result of thousand of years of interactions; their position is more like "ethnic groups" in other countries such as the US, however, since 1949, the official textbooks in China have led the consciousness of "minzu" towards "nation" and nationalism. Meanwhile, the Chinese society built upon "the nationality/minzu recognition" campaign and related policy designs of institutions in the 1950s was mainly influenced by the Soviet Union. By setting up many autonomous administrative units which consisted of $64 \%$ of Chinese territory, the Chinese nation has been turned into a state composed of 56 "nationalities/minzu."But the "nation/minzu" theories and the related institutional construction under such a political structure are possibly threats to the union of the state. This has especially become the case after the 1980s, when all social groups' "nation/ minzu" consciousness and the nationalist trend of thought were strengthened, making it of urgent importance for us to rethink "the nation/minzu" theories in China. In 2011, in a paper entitled "Whether China faces the risk of the state disintegration in the $21^{\text {st }}$ century," I analyzed the theoretical basis and the mechanisms of national collapse, using the case of the Soviet Union as a frame of reference (Ma Rong, 2011e).

Following the past readings and research, I suggested three core concepts for the "nation/minzu" studies in China: first, the dual structure of the "majority vs. minority system" in Chinese society; second, the de-politicization of "nation/minzu" issues at the level of 55 minority groups; and third, the three basic elements contributing to the political disintegration of a multi-ethnic state. Doubtlessly, we can explore further whether these concepts and opinions are accurate or not, whether terms employed are suitable or not in any specific case, and whether their logic is unassailable. These points are surely waiting to be checked by progress dynamics in social reality.

\section{Rethinking and reconstructing the discourse system of ethnic minorities}

The design of the state's structuring of "nation/nationality" after the foundation of the People's Republic of China is a two-level framework. The upper level being "Chinese nation" (zhonghuaminzu 中华民族), and the lower level being the 55 "minority nationalities" (shaoshu minzu 少数民族). This design and related systems have lasted for over six decades. After the collapse of the USSR and Yugoslavia in the early 1990s, China has also faced 
ethnic tensions and separatism in some minority regions. As people began to review the "nation/minzu" issues, they found that China must make a choice from two different policy orientations that are under the influence of two different thoughts. A change to previous policy has the ability to make the future destiny of the Chinese nation.

The first orientation is to continue Stalin's "nationality/minzu" discourse and its basic institutional policies that have functioned in China since the 1950s. According to Lenin and Stalin, all minority groups such as Ukrainians, Belorussians, Kazaks, Chechens, Georgians, Tajiks, etc. are all "nationalities" which have the right of national self-determination and of establishing their own state according to the Constitution of the USSR (Connor, 1984: 33). As Ronald Suny said, “...such concessions to the national principle [that] would lead to the consolidation of ethnicity, rather than to its disappearance, proved to be correct for the larger nationalities. Rather than a melting pot, the Soviet Union became the incubator of new nations" (Suny, 1993: 87). It is clear that this policy orientation has consecutively strengthened the collective rights and separate identity of 55 "minority nationalities," and weakened the identification of these minority groups with the Chinese nation. It must be pointed out that the first orientation even proposes to further enhance the regional autonomy and institutional construction in autonomous areas and to protect the special political rights and all kinds of collective benefits of minority groups through strengthening preferential policies toward the minorities.

The second orientation, which I support, suggests that under the preconditions of respecting the historical memories of minority groups and protecting their traditional cultures, all the issues concerned by minority elites and people such as native language learning in school, freedom of religious activities, equal rights in labor market and social welfare, etc., can be fully guaranteed by the Constitution and national law systems in China. In a modern society, all citizens should be treated equally in political, social and cultural affairs as well as in the judicial process. The most essential personal identity should be the citizenship of the Chinese nation. The government and mainstream society should treatall citizens with different ethnic background equally while encouraging the consciousness of national identity among all citizens. At the same time, the government and majority group should take all possible measures to improve the educational and employment achievements of minority members and increase their participation in the national development and modernization process. The final goal of the second orientation is to improve competition capabilities of minorities to the same level of the majority group, so that minority members can live and work as the majority group on the basis of self-respect and self-confidence. Only by this orientation can all groups in China realize the goal of sharing in the development and prosperity of the Chinese nation.

The first orientation is a continuation of the official "nation/minzu" theory and discourse constructed in the 1950s that has been implemented by the government up until today. Yet the social realities of recent years indicate that this orientation does not have the desired effect on the improvement of ethnic relations; on the contrary, it has highlighted and strengthened the identity, rights and interests gaps between different groups, promoted their distinctions with each other, constantly weakened citizenship consciousness of minority groups and their cultural identification with the Chinese nation. For the nation-building of a modern citizen state, this is lethal. One basic fact that we have to face today is, with the high speed economic development of China in the last three decades, the absolute living standard and social benefits in minority areas 
have been greatly improved, but the ethnic tensions in some areas such as Xinjiang are subsequently deteriorating. This is a very serious threat to national unity. Therefore, it is necessary to rethink the basic orientation, and the institutions and policies related to ethnic relations in today's China. This task is especially urgent at the moment.

\section{Constructinga reflexive system toward "ethnicity/minzu" issues}

In a multi-ethnic society, how can we construct a reflexive system toward "ethnicity/ minzu" issues? Based on my field research and interviews in the past three decades, several points can be raised as suggestions.

First, in order to emancipate our mind in the related debates, the studies on and discussions about "ethnicity/minzu" issues (or racial/nationality issues) should be regarded as academic topics, not politically forbidden fields. Scholars and members of the public should be allowed to think, study and discuss openly the social phenomena and theoretical issues related to ethnicity. Otherwise, there can only be official propaganda in support of existing "nationality/minzu" theories and policies. Furthermore, discussions should not be based on citations of Lenin and Stalin's works or official documents. Otherwise the debates will get far away from social reality and become completely meaningless in both academic studies and practical policy making.

Second, it is necessary to systematically analyze the issues such as: what do concepts like "race," "nation/nationality/minzu," "ethnicity," and "state" mean to the central government and all social groupsin a multi-racial or a multi-ethnic society? To the people with different ethnic backgrounds, questions related to the existence of political, social and cultural meanings of "nation/nationality/minzu/ethnicity" in peoples' daily lives and social activities can be posed. The question of how these meanings and resulting ethnic identities have been produced and fortified in the past is also important.

Third, through observation of all kinds of social phenomena, we need to systematically analyze issues such as: whether the social, political, and cultural meanings of the definition and related discourses about "nation/nationality/minzu/ethnicity" improve or obstruct communication, mutual learning and co-operation among members of different ethnic groups in their daily lives; whether the "nation/nationality/minzu/ethnicity" discourses have complicated, multiple, impacts; and what kinds of effects they produce under different social conditions during different historical periods of time. A further necessary analysis is whether the institutions for ethnic minorities and all related policies formulated by the government improve or block communication and cooperation between members of different groups in practical operations.

Fourth, on the basis of observations and field studies by scholars the discussions and debates on "nation/nationality/minzu/ethnicity" issues should be carried out among scholars and the public at both micro and macro levels including case studies, analysis of the results of institutional design and policy practice, diachronic comparisons with historical experiences in China, as well as international comparisons with other countries to learn the lessons from foreign experiences. Such discussion and debates should include the basic conceptions and the adaptability of "nation/nationality/ethnicity" discourses in China, in addition to the actual effects of all institutions and policies, summaries and reflections of the experience of successes and failures of past practices. 
Fifth, on the basis of the above studies, scholars and members of the public should discuss whether we need to adjust present "nation/minzu" theories, their related institutions and policies in a variety of fields; they should also discuss the future direction of such adjustments, discuss how to implement them and design the plans and steps as well as the timeline for implementation of such adjustments. From the discussions, it would be possible to put into practice those commonly agreed opinions, meanwhile leaving those controversial issues for further observation and discussion.

Through such procedures, the Chinese leadership, academia, and the public could gradually establish a reflexive system toward "nation/minzu" issues, knowing the peculiarities of these issues and their universalities we share with other countries. Scholars from China could further exchange Chinese experiences and opinions with international academics, letting them understand the unique history of the Chinese state in managing ethnic relations, the transformation of "nation/minzu" identifications, and the reason why Chinese scholars have to argue about "nation/minzu" theories and discuss related institutional settings and policies.

\section{Reconstruct China's "nation/nationality/minzu/ethnicity" discourse}

When we study "nation/nationality/minzu/ethnicity" issues, it is very important to establish a scientific discourse that fits Chinese history and state situation, and its contents would be enriched continually in future social practices. The writings of Marxist writers, especially Stalin, on "nation" should be studied with an eye to the historical environment and social contexts and without allowing their words to be treated as sacrosanct. At the same time, we should also absorb knowledge accumulated by scholars in the US and other industrial countries through their hundreds of years of social practices and theoretic explorations toward ameliorating racial conflicts and dealing with aboriginal natives and foreign immigrants. Meanwhile, China has a dynastic history of several thousand years in which it was a united political entity consisting of many different groups. China's long tradition of regulating and managing various groups with different languages and cultures allowed it to maintain a unified country; the surname and ethnic background of imperial families changed, but the unified political entity continued under a new dynastic name. The chronicles continued following the same structure, style, and language crossing dynasties for over 2000 years. This unique phenomenon allowed China to accumulate rich experiences in managing group relations in terms of political, economic, cultural and religious affairs. It is a great treasure that Chinese people should inherit today. China should follow its own traditional wisdom in discourse orientation, institutions and method designing. Furthermore, other developing countries, such as India, South Africa and Brazil, do have their experiences with similar problems and issues that we should absorb. Facing our ethnic interactions, if we could emancipate our minds on the relevant issues, widen our perspective and knowledge sources, and seek truth from facts, would allow China to establish an effective reflexive system related to the "nation/nationality/minzu/ethnicity" issues.

My intention in proposing to weaken the political aspect of these issues is to bring a new policy orientation to the regulating of ethnic relations in China. It doesn't mean that ethnic relations are not political, nor does it mean that there are only cultural differences among groups in China, but by this new orientation we lead the people to consider the related issues as "less-political." All issues about which minority elites and people care, 
such as group equality, political rights, policies for preferential opportunities, protection for cultures, do contain political meanings. What I suggest is to gradually lessen the "political color" of the 55 minority groups' identities and the interactions between different groups. I hope that each group would not treat itself as exceptional compared to other groups, such as by demanding independent political identity, special political rights, or enjoying specific privilege policies. I hope that Chinese society would not approach inter-group relations from the perspective of "political bargaining," "area distinction," "rights division," or "benefits clash." I hope that Chinese people don't bring group prejudice and the essentialist ways of thinking about nation/ethnicity to the twenty-first century to destroy the new opportunity of historical development and the close cooperation and co-prosperity of the Chinese nation.

My suggestions for reconstructing "nation/nationality/minzu/ethnicity" discourse in a Chinese style are as follows:

\section{First, to deal with "nation/nationality/minzu/ethnicity" issues with the principles of a modern citizen-state and of a society ruled by law}

Contact and co-operation between members of different groups can involve a series of comprehensive and complicated issues. Economic exchanges, for example, concern practical interests and bring about disputes; cultural interactions between highlight different of cultural traditions due to language, religion and customs, and can give rise to conflicts of values. Such problems cannot be resolved through political means alone, they have to be dealt with by related policies and national laws that cover all sectors of the society: economy, culture, language, religion, judiciary, and social participation, etc.

Since the 1950s, Chinese people have believed that all interactions between different groups are issues of "ethnic relations," and issues such as criminal cases, civil disputes, economic disputes, and customary differences have been brought to the political level as an "ethnic relation" problem needing a solution. This has forced members of minority groups to "politicize" non-political issues and seek political means, in the name of "implementing minority policy," to solve the problems. The government at all levels, dominated by Han majority officials, also habitually treats all such issues as "ethnic issues." These officials usually employ special and political methods of "implementing minority policy" while neglecting a whole set of national laws and regulations to deal with problems among citizens. This results in minority groups becoming "special citizens" subject to a series of special regulations ("minority policies") while the national laws and regulations are disregarded. A typical case of this phenomenon is the event of the "astronomically-priced Xinjiang nut cake". In that case, in Hunan in 2012, a Uyghur street vendor received over 30,000 US dollars as "compensation" for damage done to his cakes by a Han customer, based on the local court verdict. ${ }^{1}$ The court ordered an ethnic-majority member to pay as much as a minority member demanded. The effect of this case was that many Han people refused to patronize the businesses of Uyghur vendors. The case is the embodiment of the "politicization" of ethnic issues in present-day China.

In these institutional structures and the implementation of a variety of policies, there are discrepancies in the political rights and benefits given to "minority groups" and Han majority. In some minority autonomous regions, the same policy discrepancies could also be observed between "autonomous minority groups" and "non-autonomous 
minority groups", such as Uyghurs vs. Kazaks, Mongols and Kirghiz in the Xinjiang Uyghur Autonomous Region. Such institutional and policy designs serve to treat ethnic relations as "political relations" leading to each group striving to for augment its own population size and proportion in the region's total population; to endeavor to apply for setting up new autonomous regions for themselves and to enlarge their geographic scope; to increase their "autonomous rights and prestige" and other interests through intensifying autonomous institutions; and to aggrandize all kinds of preferential policies that aim at their own members and to enhance the executive ability to implement them. Furthermore, many people are inclined to treat all troubles taking place between officials and common people of different groups in daily communications from the political perspective of "nationality/minzu issues and contradictions." Such a "politicized orientation" inevitably creates greater obstacles to the ability of government at all levels to find common solutions to the inter-group issues.

At the same time, those "non-autonomous minority groups" in the same region unavoidably try to protect their own groups' rights, fighting for higher positions and decision-making powers for their representatives. In policy discussions, these representatives endeavor to gain as many rights as possible for own people and their inhabited regions. This turns the interactions between ethnic groups into competitions, creating a contending arena for power and interests. In this process, the consciousness of "nation/minzu" of all groups is stimulated and reinforced, creating a "zero-sum" game. This direction should not be one for a modern republic citizen state takes. It is not an ideal social structure either.

This growing competition for power and self-interest among ethnic groups is adverse to the union of Chinese nation and the state, and to the realization of the equality and justice among all citizens across the country. On the contrary, the orientation to de-politicize non-political civil issues aims to deal with or solve them through national laws and through notions of a modern citizen state and rule-by-law society.

The reason I put forth this orientation for de-politicizing ethnic issues is in the hope that elites and common people of all groups in China might think about the future direction and result of the transformation of ethnic relations.

\section{Second, to insist on fighting against "Han chauvinism"}

As Han is the majority group in China with a population of more than 1.2 billion, with a more developed economy and greater access to technology than other groups, and being powerful in all social aspects, undeniably some Han people, whether consciously or unconsciously, maintain prejudice and discrimination toward minority groups. Some of them rudely adopt a critique of whether minorities can master the Putonghua language or whether they accept traditional culture of the Han majority in their evaluations of minority groups. They view the traditional cultures and economic activities of minority groups in a condescending way, employing the unilinear evolutionism to appraise them as being "advanced" or "backward." Many of them don't know and don't want to know the traditional cultures and religions of minority groups, having a sub-consciousness of ingrained "Han Cultural centrism."Few Han members living and working in the western part of China actively learn minorities' languages; the government's department of cultural advertisement pays less attention to minority groups and the fact of China's cultural 
diversity; TV stations, for example, seldom hire minority employees; some Han officials, in their hearts, distrust minority officials; in universities, the personnel departments and admissions offices often reject minority teachers and students with an indifferent attitude of "following the rules"; some enterprises led by the central authorities and Han entrepreneurs do not take into account the participation of local minorities and their share in the interests when they develop resources and make businesses in minority regions. These embodiments of "Han chauvinism" inevitably have negative impacts on the ethnic relations in China. The recent deterioration of these relations in some of the western regions is more or less connected with the above-mentioned behaviors.

From an analysis on the macro-level using census data, such as structures of educational achievement and the occupational compositions of labor, and from my personal experiences of interviewing local cadres and people in the western regions, the "marginalization" of minority groups during the last 10 years has been aggravated by such attitudes and practices. During 2000-2010, for example, the percentage of Uyghurs who are "leaders in the offices of the Party, the government and enterprises" relative to all employed Uyghurs above the age of 16 , decreased from $0.84 \%$ to $0.47 \%$, while the absolute number decreased 32.3\% (Ma, 2013a). A similar situation can also be observed among Mongolians and Tibetans. These statistics reflect a trend toward the marginalization of minority cadres. The percentage of Uyghur professionals (doctors, teachers, scholars, etc.) and workers in manufacturing and construction among all employed populations decreased prominently as well. The employment issues of Uyghur and Tibetan college graduates are much more severe than Han graduates. The difficulty western minority members in urban parts of China have in finding employment and making an adequate living is much greater than Han migrant laborers. Meanwhile, the gap in faculty, teaching and research achievements between universities in the western part of China and those in the east coastal cities is enlarging.

These are many cases of the marginalization of minority groups in the western part of China during the process of the social economic development and modernization of the state. It is natural for minority elites and people to worry about their future. The central government and mainstream society must pay close attention to the marginalization in the last 10 years and should try to change the trend as soon as possible.

So the basic social precondition for realizing the de-politicization of ethnic issues is for Han officials and people to treat minority officials, intellectuals and ordinary people with an attitude of mutual respect, equality, love and help. If there's no such precondition, and if we don't engage in introspection and eliminate the "Han chauvinism," prejudice, and discrimination that is deeply held by people across the country, then the goal of improving ethnic relations in China will be impossible.

The negative attitude some Han people in minority regions have toward local minorities comes partly from their discontent with "privilege policies for minorities". For example, some Han think that preferential policies such as weighted scores that favor minority students' university entrance exams are not fair. I frequently hear from Uyghur students coming from Xinjiang that Han in inland China are much more friendly than Han in Xinjiang. One reason for this might be that the latter feels that they and their children are discriminated against by such Xinjiang minority preferential policies. The minority students with scores more than one hundred points lower than Han students, for 
example, are admitted to key national universities, while the Han students fail to gain university admission and instead have to find work (Ma Rong, 2009). Psychologically, they feel this sharp contrast is unacceptable. The same type of situation can be observed from the judicial policy of “two less and one lenient (两少一宽)" ${ }^{2}$ In the same way we used to ask Han members to understand the minority's situation and feelings from their positions, I would suggest members of minority groups also try to understand the feelings of Han and their situations from their positions. With such a transposition, when some minority scholars strongly propose to reinforce further privilege policies toward minorities, they should be more circumspect. Only when we are empathic toward each other, can we understand each other.

In the western regions of China, the discontent and mind-set of disequilibrium found in local Han people is embodied through their attitudes toward minorities in employment and all kinds of procedures. Meanwhile, there are many fewer minority people in eastern China, so Han in the east China do not feel the impact of such privilege policies and are more likely to treat minorities with a normal attitude. With more and more rural minority members migrating to cities in eastern China, if events like the "astronomically-priced Xinjiang nut cake" appear more and more often, it is predictable that Han residents in eastern China would gradually change their attitudes. The preferential policies in favor of minorities are complicated issues formed in the past, they brought both positive and negative impacts to ethnic relations; what we need to do is to study how to adjust them in a gradual and smooth way.

\section{Third, rethink the adjustment of ethnic relations from a long-term perspective}

When we review the historical process of the development of a society, we must pay attention to multiple aspects: the macro-aspect of the general direction of its historical development and the micro-aspect of all kinds of detailed specific issues taking place at the present time. Of the two, we should first make sure of the former, recognizing the general orientation of the history before we think about what we should do in dealing with detailed events today. A person must know where to go when she or he is walking. After a careful analysis of the Soviet Union that composed of many units and finally collapsed in the 1990s, and a study of the United States whose racial tensions are generally improved since the Civil Right movement in the 1960s, I suggest to a de-politicization of the ethnic/minzu issues in China and a rethinking of the historic orientation of the Chinese nation in the long run.As a country of 1.3 billion people, it is impossible to develop without long foresight and related strategic design.

China should act against the "Han chauvinism" and the cultural assimilation of minority groups by the majority. At the same time, the Han majority is not to be equated, alone, to the "Chinese nation", Han culture is not equal to "Chinese culture." The cultural strategy of the twenty-first century of China is to build a total "Chinese culture" that includes all 56 groups. This is a macro, forward-looking strategy for cultural development in the long run.

On the other hand, nowadays we have to face all kinds of concrete, recently emerged, social events as we deal with issues of local governments, people's experiences and urgent complaints. The issues include: the marginalization of minority cadres, the weakening and marginalization of minority languages in public communications, the contraction and 
weakening of the market for minority traditional culture, the adjustment of bilingual education policies, the marginalization of young minority people and college graduates in the job market, the regulation of mass religious activities in minority regions according to law, the poverty alleviation of peasants and nomads in remote regions, the ecological damage due to natural resource extraction, the protection of traditional architectures in reconstructing old urban districts, and other livelihood issues. The government officers at all levels must pay high attention to these micro issues. On the basis of in-depth investigations and discussions that include minority elites, these issues and relevant proposals should be brought up with minority cadres, intellectuals and the public to discuss, negotiate and get more suggestions before implementing them. In dealing with emergencies, they should adopt suggestions from minority cadres and the public to solve problems appropriately. The solution must gain understanding and support from most of the local populace. If our work in this field is not meticulous and thorough, and if the scope of people from whom we seek suggestions and advice for proposals for solving problems is too narrow, if the proposed schedules are not understood and accepted by most local people, those concrete social contradictions might emerge in the forms of "ethnic contradictions" or "religious contradictions."

\section{Conclusions}

In the face of the serious situation of maintaining social stability in western China, we should recall what the CCP and the the PRC government accomplished with ethnic minority people in the 1950s, and what was the basic position and attitude of cadres and the soldiers toward common Tibetans, Uyghurs, Mongolians, and other minority groups in the southwest. At that time, the slogan was "serve the people," and Han cadres and soldiers who entered Xinjiang and Tibet actively studied minority languages, respected local people's religions and customs, strived to solve difficulties local people had in their lives (food, housing, and medical care), while at the same time they respected community leaders and prestigious religious figures, and humbly listened to their opinions and suggestion. Their attitude and behavior got positive results, winning the favor of most minority elites and common people, quickly and successfully allowing for the great course of the peaceful union of China, eliminating local bandits and reactionaries who were against the new government, establishing the administrative system in a short period. At that time the central government didn't have many financial resources and economic strength, but the government won the massive support of the minority people.

Today, we must go back to this good tradition, making the emphasis of our work on the winning of people's hearts and support instead of simply using economic benefits and security control as the main means to maintain social stability. If the government's ways of doing things and its methods are far removed from the needs of minority groups, our work on ethnic relations deviates from the right direction. If, as we always say, our purpose is to "serve the people," then who are the people? This is not an abstract concept. The populations who make up all groups across the country, such as Uyghurs, Tibetans, and Mongols, are the people. They are the subjects we rely upon and we serve; the officers of all levels of government are their "public servants." If we are confused about this, we can do nothing. 


\section{Endnotes}

${ }^{1}$ Available at https://baike.so.com/doc/5388168-5624743. html.

${ }^{2}$ In 1983, the central government of China issued the No. 5 document, it required that when minority members are involved in judicial cases, the police department and court should arrest less, execute less, and the verdict should be lenient. Available at https://baike.so.com/doc/6678981-6892864.html.

\section{Competing interests}

The author declares that he has no competing interests.

\section{Publisher's Note}

Springer Nature remains neutral with regard to jurisdictional claims in published maps and institutional affiliations.

Received: 1 July 2017 Accepted: 8 September 2017

Published online: 18 December 2017

\section{References}

Connor, Walker. 1984. The National Question in Marxist-Leninist Theory and Strategy. Princeton: Princeton University Press. Gellner, Ernest. 1983. Nations and Nationalism. New York: Cornell University Press.

Hobsbawm, E.J. 1990. Nations and Nationalism since 1780. Cambridge: Cambridge University Press.

Hu, Angang, and Lianhe Hu. 2011. The Second Generation of minzu Policy: Promote Ethnic Integration and Prosperity as a Single Body. Journal of Xinjiang Normal University 5: 1-12.

Kedourie, Elie. 1960. Nationalism. New York: Frederick A. Praeger Publisher.

Leibold, James. 2013. Ethnic Policy in China: Is Reform Inevitable? Vol. 68. Honolulu: East-West Center Policy Studies.

Ma, Rong. 1991. Han-Tibetan Residential Patterns in Lhasa. The China Quarterly 128: 814-835.

Ma, Rong. 2000. Several Issues about ethnicity Studies. Journal of Peking University 4: 132-143.

Ma, Rong. 2003. Economic Development, Labor Transference, and Minority Education in the West of China. Development and Society 32 (2): 125-143.

Ma, Rong. 2004. A New Perspective in Guiding Ethnic Relations: the De-politicization of Minority Ethnic Groups. Journal of Peking University 6: 122-133.

Ma, Rong. 2007. Bilingual Education for China's Ethnic Minorities. Chinese Education and Society 40 (2): 9-24.

Ma, Rong. 2009. The Development of Minority Education and the Practice of Bilingual Education in the Xinjiang Uyghur Autonomous Region. Frontiers of Education in China 4 (2): 188-251.

Ma, Rong. 2010a. Another 'Dual Structure' in Chinese Society. Journal of Peking University 3: 93-103.

Ma, Rong. 2010b. About Writings on national Issues by Lenin and Stalin. Scientific Socialism 2: 23-25.

Ma, Rong. 2011a. Population and Society in Contemporary Tibet. Hong Kong: Hong Kong University Press.

Ma, Rong. 2011 b. Urban Development and Bilingual Education in Xinjiang: Two Research Reports. Northwestern EthnoNational Studies 2011 (2): 159-172

Ma, Rong. 2011 c. Income Gaps in Economic Development: Differences among Regions, Occupational Groups and Ethnic Groups. ProtoSociology 28 China's Modernization I: 101-129.

Ma, Rong. 2011 d. Rethinking of Economic and Social Impacts of Government Managed Tibet-Assistance Projects. Qinghai Journal of Ethnology 2011 (4): 61-64.

Ma, Rong. 2011 e. Whether China faces the risk of the state disintegration in the $21^{\text {st }}$ century. Leaders 38: 88-108 No. 39 , pp. $72-85$.

Ma, Rong. 2012. "How to understand 'nation' and 'nationalism in Marx and Engels' works". Chinese Academics, No. 32. Beijing: Commercial Press, pp. 146-219.

Ma, Rong. 2013a. The Change of the Occupational Structure and Cross-Region migration of Minority Labors: An Analysis of the 2010 Census. Journal of South-Central University for Nationalities 4: 1-15.

Ma, Rong. 2013b. A Han vs. Minorities Dual Structure of Chinese Society. China: An International Journal 11 (2): 7-24.

Ma, Rong. 2014. Reflections on the Debate on China's Ethnic Policy: My Reform Proposals and Their Critics. Asian Ethnicity 15 (2): 237-246.

Ma, Rong. 2015. Keep the Same Flag, Stabilize the Position, Adjust Orientation, and Reform Practically: An Interpretation to the Minzu Work Conference by the Central Committee of CCP. Qinghai Journal of Ethnology 2: 82-90.

Ma, Rong, and Naigu Pan. 1988. Han and Mongol Intermarriages in Rural Chifeng, Inner Mongolia. Journal of Peking University 1988 (3): 76-87.

Ma, Rong ed. 2016. The Mechanism and Social Results of Inland Education: The Studies of Inland Tibetan and Xinjiang Schools. Beijing: Social Sciences Academic Press.

Shiyuan, Hao, et al. 2013. Construct a New Type of minzu Relations. Leaders 53: 79-100.

Stalin. 1942. Marxism and the National Question: Selected Writings and Speeches. New York: International Publishers.

Suny, Ronald G. 1993. The Revenge of the Past: Nationalism, Revolution, and the Collapse of the Soviet Union. Stanford: Stanford University Press.

Yonghao, Du. 2010. Huaxia-Han, Chinese nation, and Chinese people. Studies on Minzu Work 4: 11-21.

Zhu Weiqun, 2012. "Several Points on the Present Issues in the minzu Field". Study Times, Feb. 13. 